\title{
Name Selection in International Branding: Translating Brand Culture
}

\author{
Jiafeng $\mathrm{Liu}^{1,2}$ \\ ${ }^{1}$ School of English for International Business, Guangdong University of Foreign Studies, Guangzhou, China \\ ${ }^{2}$ School of Foreign Languages, Southwest University for Nationalities, Chengdu, China \\ Correspondence: Jiafeng Liu, School of English for International Business, Guangdong University of Foreign \\ Studies, Guangzhou, China. E-mail: 378411817@qq.com
}

Received: January 15, 2015

Accepted: January 5, 2015

Online Published: March 27, 2015

doi:10.5539/ijbm.v10n4p187

URL: http://dx.doi.org/10.5539/ijbm.v10n4p187

\begin{abstract}
Brand culture is the soul of the brand, and the brand name is the direct manifestation of the brand culture which affects the translation of the brand name in international branding. However, little research has been done (1) on the brand culture represented by the brand name or (2) on how to deal with the brand culture represented by the original brand name in translating process. Based on the empirical evidences of the Chinese translation of some famous English brand names, the author first identifies the brand culture represented by the brand names, and proposes that the repositioning of the brand culture plays an important part in international branding, and finally put forward the strategies of translating brand culture in the process of brand name selection.
\end{abstract}

Keywords: brand name, brand culture, brand name selection, translation, repositioning

\section{Introduction}

In the era of globalization, more and more companies provide their products and services across markets where languages and cultures are different. That means most of the brands, originating from a particular cultural context and a significant part of their brand equity is tied to the culture represented by the brand names, have to reexamine and reposition their brand culture to determine an appropriate brand name translation. Brand name translation is significantly affected by the brand culture and at the same time affecting the consumers' recognition and identification of the brand culture. Consequently, how to translate the brand culture represented by the original name has become one of the key issues in the research of international branding. However, there are few studies on brand culture represented by the brand name or on how to convert the brand culture represented by the original brand name to the translated version in target language. With the Chinese name selections of some well-known world brands, the purpose of this research is to explore the strategies to deal with the brand culture in the process of brand name translation. For this purpose, Section 2 has a literature review on brand naming in international branding. Section 3 identifies and repositions the brand culture represented by the brand names in international branding. Section 4 puts forward the strategies of converting the brand culture represented by the original brand name into the translated version.

\section{Literature Review}

The vast literature on brand naming in international branding generally addresses three issues: the criteria for good brand names, factors affecting brand naming, brand name translation, in particular on the complex issue of translating a name from English (an alphabetic language) to Chinese (a character-based language).

In terms of the criteria for good brand names, many authors have researched what makes a good brand name (Peterson \& Ross, 1972; Colins, 1977; McNeal \& Zeren, 1981; McCarthy \& Perreault, 1987; Robertson, 1989; Chan, 1990; Keller, 1993). For instance, Peterson and Ross (1972) note that English brand name selection should be built on familiar words because consumers may already have positive notions about such words that may help them to recognize and recall the brand name. Robertson (1989) suggests that a desired brand name should be simple, distinctive, meaningful, emotional, associated with the product class, eliciting a mental image, making use of the repetitive sounds, morphemes and phonemes. Upon analyzing the desirable qualities summarized by McNeal and Zeren (1981), many authors, such as McCarthy and Perreault (1987), Colins (1977) and Armstrong (1997), Chan and Huang (1997), categorize the criteria for good brand names into three components: marketing, legal and linguistic. As far as marketing aspect is concerned, a good brand name could realize the functions of sales promotion, advertisement and persuasion, suggest product benefits, be suitable for packaging and support 
the desired company image and the desired product image. As far as legal aspect is concerned, a good brand name should be legally available for use and unique in competition. As far as linguistic aspect is concerned, a good brand name should be easy to spell, read, pronounce and remember. Particularly, the linguistic aspect of a good brand name in Chinese is of two-syllable length, $\mathrm{H}-\mathrm{H}$ tone combination, positive connotation, and noun-noun morphemic structure. Chan and Huang (2001a, 2001b) also suggest that Chinese brand translation should relate to the syllabic, tonal, compound structure, and semantic preferences of the Chinese.

In terms of the factors influencing brand naming in international branding, the major research focus has been on marketing, linguistic and cultural factors across markets (Dong \& Helms, 2001). The marketing factors generally include the local market conditions, consumer characteristics, brand strategies, product qualities. The local market conditions and brand strategies are key factors to decide the degree to which the brand name will be standardized or localized (Francis, Lam, \& Walls, 2002). The combined effects of the consumers' educational background (extent of bilingualism) and product physical quality affect the choice of translation decision (Hong, Pecotich, \& Schultz, 2002). The linguistic factors mainly refer to language differences such as those between English and Chinese, which require the translation readable and melodious and universally convertible in sound, short and easy to remember in form, and positive in meaning (Ren, 2002; Li \& Shooshtari, 2003). Francis, Lam, and Walls (2002) have investigated the brand name standardization/ adaptation strategies used by consumer goods Fortune-500 companies in China and Hongkong. They find the writing system, the core concept of the brand reflecting the brand's positioning and the values and attributes it represents, and the implementation of the brand are all key linguistic differences that would affect the decision to standardize or localize when translating the brand name from English to Chinese. Li and Shooshtari (2003) compare the socio-linguistic differences between Chinese and English and suggest the combination of words that would differentiate the product as well as the sound should be emphasized in the search for an appropriate Chinese translation. Most Americans favor brand names with a sound that appeals to them while most Chinese prefer brand names that provoke visual images and indicate moral or value orientations. With the examples of branding and translation blunders mentioned in international business texts and popular press books, the major research of cultural factors addresses the influences of historical, political and general cultural factors on brand name translation (Dong \& Helms, 2001; Li \& Shooshtari, 2003).

In terms of brand name translation, the major research has focused on translation methods and how these methods influence brand equity, especially from alphabetic to character-based languages such as Mandarin. For example, Hong, Pecotich and Schultz (2002) hold that there are usually two generic methods of brand name translation: (1) direct translation for the meaning of the brand name and (2) phonetic translation for the pronunciation of the brand name. Dong and Helms (2001) treat translation as a general term that includes both free and literal translations, summarized the various types of translation-free translation, literal translation and creative translation, and examine the influence of brand names on brand equity by analyzing the various types of brand name translation. According to Schmitt and Zhang (2012), brand name translation can be analyzed along two linguistic dimensions: relatedness in sound (that is, phonemes) and relatedness in meaning (that is, semantics), which yields four possible types of name translations from English to Chinese: a translation based on sound; a translation based on meaning; a translation based on sound and meaning; creative translation. Considering all the factors influencing international brand naming, firms appear to be successful in avoiding unfortunate brand name mistakes and add features to the brand names, such as cultural symbols, additional product benefits, and more positive connotations, when localizing the brand name for the Chinese market (Francis, Lam, \& Walls, 2002).

From these studies on the brand naming in international branding, it can be seen that these researches mainly focus on the characteristics for good brand names, the factors affecting brand naming, and the translation methods and how these methods influence brand equity, which have improved and deepened the understanding to and the research on the translation of brand names. They may be the guidance and reference for the future translation of brand names. However, researches on cultural factors mainly consider the influence of general cultural differences, especially that of cultural taboos, on the naming and translation of brand names, and seldom mention the influence of specific cultural differences, such as brand culture, on the translation of brand names.

In today's marketing context, brand culture has become the soul of the brand, and the brand name is the direct manifestation of the brand culture. Therefore, the in-depth study of the impact of brand culture on the translation of brand names is of great importance. 


\section{Brand Culture Repositioning}

\subsection{Brand Culture}

A Brand can be defined as "the name, term, sign, symbol, or design, or a combination of them, intended to identify the goods or services of one seller or group of sellers and to differentiate them from those of competitors" (Kotler, 1991). A brand has been naturally associated with culture from the time it came into being and reflects the culture and values of the organization. The name, color and symbol of the brand are all the manifestations of culture. Brand culture refers to the cultural traits, including all the cultural phenomena such as the deposition of the sense of business, value and aesthetics in the brand and the brand management, and the benefit cognition, emotional attributes, cultural traditions and individual images they represent (Zhou et al., 2002). A company's true values are the soul of its brand culture. The purpose of the brand culture construction is to establish common values and behavior standards to match the brand and the identity of the consumers so as to allow the brand and the consumers to enter the world of each other and to construct a solid long-term relationship between the brand and the consumers. Successful cases are such brand names as Coca-Cola, Apple Computer, Harley-Davidson and a series of other well-known international brands. They have basically no difference from other less well-known brands in terms of quality and performance, but their prices are much higher. The reason why they can still attract the consumers is that these brands have created their own brand culture which is aligned with the consumers' values to form a lifelong belief in the brand culture. It is this kind of brand culture that attracts them to willingly pay the high brand premium.

\subsection{Brand Culture Represented by Brand Names}

Brand name is the core part of the brand. It was first used as the product label to differentiate one product from another. With the evolution of branding, the brand name has become the direct manifestation of the brand culture and expressed the values of the producer and the positioning of the product in the market as well as conveying a specific set of attributes and benefits to buyers. When the values and culture-specific meanings reflected by the sound and/ meanings of the brand name resonate with the core values of target consumers, the brand name will not only allow consumers to clearly identify and remember the benefits and the characteristics of the brand, but become a driving force for the consumers' acceptance. That is, the brand culture represented by a brand name usually includes the values and cultural-specific meanings reflecting the brand positioning of a brand.

\subsection{Brand Culture Repositioning}

Consumers' core values drive their brand choice and influence their ongoing perceptions of the brand culture. When the brand culture is in line with the consumers' culture and their sense of values, the impact of the brand on the consumers will be very strong (Miller \& Muir, 2004). However, when a brand is trying to enter a new market where language and culture are different, the company has to reexamine whether the brand culture of the brand is well-positioned. Accordingly, the company has to reexamine whether the values and culture-specific meanings reflected by the sound and/ meanings of the brand name cater to the needs of the target consumers. If the original culture embodied in the brand has to be adapted to resonate with the culture of the target consumers in the target market, the translation of the brand name should also reflect this adaptation, which will be helpful for the target consumers' positive perception and recognition of the brand.

Therefore, when a brand tries to enter a new target market, it will have to systematically investigate and understand the culture background of the new target market, such as the national culture and the consumers' culture. It then repositions the original brand culture to create a new brand culture in line with the target market culture and the sense value of the consumers to reflect the aesthetic experience and consuming psychology of the target consumers. As Banerjee (2008) puts it, for marketing in a particular country, the match of the original brand culture and the specific culture of the country should be taken into consideration. Using corresponding brand culture strategies will be able to achieve better marketing effectiveness (Miller \& Muir, 2004). Accordingly, the values and culture-specific meanings in the original brand name should be repositioned to create a target customer-focused value proposition.

\section{Translating Brand Culture}

As the brand name is the direct manifestation of the brand culture, the translation of brand names should focus on the core positioning of the brand to show the brand's unique cultural charm as much as possible. Therefore, two principles should be adhered to in the selection of brand names: (1) the maintenance of the original brand core values or culture-specific meanings that can lead to the positive recognition of the target consumers; (2) the absorption of the new brand core values or culture-specific meanings that are positive to the consumers' value orientation and aesthetic psychology. Under the guidance of these principles, the impact of the repositioned 
brand culture on the translation of the brand names in the target market is represented as the following four aspects: (1) maintaining the original core brand values or culture-specific meanings; (2) augmenting the original core brand values or culture-specific meanings; (3) abandoning the original culture-specific meanings negative to the target consumers; and (4) infusing the new core brand values or positive culture-specific meanings.

\subsection{Maintaining the Original Core Brand Values and Culture-Specific Meanings}

In the process of repositioning the brand culture, the target consumers may be positive to certain values and culture-specific meanings conveyed by the original brand name and such values and culture-specific meanings can reflect the core brand positioning of the brand. Therefore, these core brand values and culture-specific meanings should be maintained in the translation of the brand names. This can contribute to the recognition and identification of the brand.

Take for example this situation. Nestle is the world's leading nutrition, health and wellness company now. However, since it was established in 1867 when Nestle just produced and sold infant-food, nutrition has been the cornerstone of Nestle. This corporate brand is endeavoring to give consumers tastier and healthier products to enjoy at every eating occasion and throughout life's stages including times of special nutritional need. The corporate brand name "Nestle" was originally the name of the founder of the company, and it shares the same root of the English word "Nest". That is why a nest image is used as its trademark, meaning its cultural connotation is positioned in "comfort" and "snuggery".

Since Nestle entered China market, it has got a Chinese translated name “雀巢”. The Chinese translation “雀巢” is closely related with the image of "Nest", which reminds Chinese consumers of the brand seeing this image. This fully embodies the original cultural connotation of "comfort" and "snuggery" as well as the core brand values of "nutrition, health and wellness", and plays a vital part for the success of the Nestle products in the Chinese market.

\subsection{Augmenting the Original Core Brand Values and Culture-Specific Meanings}

During the evolution of corporate branding, by creating ads and many commercials, brands have accumulated rich brand culture of unique charm and acquired desired core brand values and culture-specific meanings. However, these meanings, reflecting the core brand positioning of the brand and also attracting the target consumers in the new market, maybe not be reflected by the pronunciation and/or meaning of the brand names. Therefore, it is necessary to augment the original core brand values and culture-specific meanings in the translation of the brand names.

Coca-Cola, an American corporate brand, originates from a kind of drink with "Coke" leaf as its raw material. The brand name itself has no specific meaning or implication except for referring to the function of the drink. Mercedes-Benz, a famous automobile brand in the world, was originally the name of the boss's daughter. It carries no cultural meaning of the brand either. However, these brands have experienced specific historical events with specific consumers and unique brand stories. With the emergence of advertising, they have acquired a particular meaning and character over time and have slowly accumulated their rich brand culture of unique charm. In this era taking brand culture as the soul of the brand, when these brands enter into a new linguistic and cultural target market, it is necessary to augment particular cultural connotations in line with the brands' core positioning for the target consumers' recognition and identification. For example, "Coca Cola" is transliterated as “可口可乐”, which means “Can-Be-Tasty-Can-Be-Happy" (Alon, Littrell, \& Chan, 2010) and augments the original core brand values of "passion", "optimism" and "fun". "Mercedes-Benz" is translated as "奔驰”, sounding the same as the last part of the original brand name, and augmenting the original cultural concept of "happy" and "efficient". This is in line with the Chinese culture and enables Chinese consumers to appreciate the speed of the car. Ikea is a furniture brand, and even in Sweden, there are very few people knowing its meaning. "Ikea" is a combination of the initial letters of the founder's name "Ingvar Kamprad", his farm name "Elmtaryd" and the village name "Agunnaryd". However, when entering the Chinese mainland market, the corresponding Chinese translation “宜家” is a very good manifestation of the original brand culture. IKEA's vision is "to create a better everyday life for the many People", which is interpreted as a combination of the goal to improve people's lives with the necessary means to achieve this - making good profits and minimizing costs. It is very easy for people to perceive its commitment to quality and innovation, and to identify and accept its brand culture.

\subsection{Abandoning the Original Culture-Specific Meanings Negative to the Target Consumers}

In the process of repositioning the brand culture in the new market, some original culture-specific meanings reflected by the sound or meaning of the brand name are in conflict with the national culture or consumer culture 
while the original core brand values fit those of consumers. Therefore, the negative culture-specific meanings should be abandoned while the positive original core brand values are kept.

Poison is a brand name of perfume launched by C.D. in 1985. The use of the word with extreme meaning as a brand name is said originated from the tragic story of Romeo and Juliet. The cultural meaning carried by this brand name is a reflection of the women's pursuit of wild beauty. It is also an indication that after using such a perfume, a woman can make a man captivated and unable to forget her. This is why the brand of perfume is so acclaimed in the west countries. However, this cultural connotation is in conflict with Chinese culture. It will have a totally different association. For example, it will be a reminiscent of "the roots of troubles". If you do not abandon the cultural connotation, it will be difficult to win the market share in China. So, considering the cultural orientation of Chinese consumers and their aesthetic psychology, it is translated as “百爱神”or “百爱”, reminiscent of "much-beloved". This translation is understandable and meets the Chinese women's psychology to pursue gentleness and skillfulness. Opium, another brand name of perfume, has the cultural connotation of “extreme temptation" in the French culture. However, if it is literally translated as “鸦片”, the original cultural connotation has changed in the Chinese cultural context, because this word will remind Chinese people of their humiliation in the Opium Wars, which were fought between Britain and China over their viewpoints on diplomatic relations, trade, and the administration of justice for foreign nationals. So strong a sense of national pride has made the perfume violently criticized by the Chinese consumers and prohibited to sell ultimately for violating China's trademark law. Therefore, it is necessary to abandon the original brand cultural connotation sometimes in translation.

\subsection{Infusing the New Core Brand Values or Culture-Specific Meanings}

In the process of repositioning the brand culture, when the original core brand values or culture-specific meanings could not meet the needs of the target consumers in the new market, it is necessary to infuse the new core brand values or culture-specific meanings into the translated name.

Acura is the name of a Japanese luxury automotive brand. On the one hand, Acura is clearly suggestive of the word accuracy. On the other hand, the brand name morphologically suggests the perceived qualities of both Italian and Japanese cultures at once-artistry and scientific precision (Danesi, 2013). When Acura was introduced into China in 2006, it reexamined and repositioned its core brand values and culture-specific meanings, and got “讴歌” as its Chinese translated version, meaning "praise; celebrate", which is associated with the attitudes of the target consumers in China "full of pride and joy of life; positive". Procter \& Gamble, a great brand name of daily commodities established in 1837, attached great importance to the Chinese market culture when it first entered the Chinese market. After careful study of the culture and psychology of Chinese consumers, the company integrated and repositioned its original brand culture, and offered “宝洁” as the Chinese translation of the brand name in compliance with the local consumers. “宝” means “precious” and “洁” “cleanness”. “宝洁” stands for “precious cleanness and fits the cultural values of Chinese consumers. Consequently, it finally won the success in the Chinese market. Johnson \& Johnson, founded in 1887, is an American company engaging in medical and health care products. The brand name is the last name of the founders of three brothers. The translator took the positioning of brand market into consideration and translated it as “强生” in Chinese. This translation infuses an element of Chinese culture in the original brand name and produces a sense of "strong" and "vitality". This translation is in close association with the products of medical and health care.

\section{Conclusion}

Brand culture is the soul of the brand. The repositioning of brand culture determines the translation of the brand name, which in turn determines the success of the products in the target market. Therefore, it is of great importance to reposition the brand culture for the acceptance of the target consumers. Four translation strategies are then proposed based on the successful repositioning of the brand culture in this paper: maintaining the original core brand values or cultural-specific meanings, augmenting the original core brand values or cultural-specific meanings, abandoning the original negative cultural-specific meanings and infusing the new core brand values or cultural-specific meanings. Only with these four strategies can a brand name be translated successfully.

\section{Acknowledgements}

This paper is sponsored by National Social Science Foundation of China (Grant No. 13BGL066).

\section{References}

Alon, I., Littrell, R. F., \& Chan, A. K. K. (2010). Branding in China: Global Product Strategy Alternatives. 
Multinational Business Review, 17(4), 123-142.

Banerjee, S. (2008). Strategic Brand-Culture Fit: A Conceptual Frame Work for Brand Management. The Journal of Brand Management, 15(5), 312-321. http://dx.doi.org/10.1057/Palgrave.bm.2007.10

Chan, A. K. K., \& Huang, Y. Y. (1997). Chinese Brand Naming: From General Principles to Specific Rules. International Journal of Advertising, 16(4), 320-335.

Chan, A. K. K., \& Huang, Y. Y. (2001a). Principles of Brand Naming in Chinese: The case of drinks. Marketing Intelligence \& Planning, 19(5), 309-318.

Chan, A. K. K., \& Huang, Y. Y. (2001b). Chinese Brand Naming: A Linguistic Analysis of the Names of Ten Product Categories. Journal of Product and Brand Management, 10(2), 103-119.

Chan, K. K. (1990). Localization in International Branding: A preliminary Investigation on Chinese Names of Foreign Brands in Hong Kong. International journal of Advertising, 9(1), 81-91.

Dong, L. C., \& Helms, M. M. (2001). Brand Name Translation Model-A Case Analysis of US Brands in China. Journal of Brand Management, 9(2), 99-115.

Francis, J., Lam, J., \& Walls, J. (2002). The Impact of Linguistic Differences on International Brand Name Standardization: A Comparison of English and Chinese Brand Names of Fortune-500 Companies. Journal of International Marketing, 10(1), 98-116.

Hong, F. C., Pecotich, A., \& Schultz, C. J. (2002). Brand Name Translation: Language constraints, product attributes, and Consumer Perceptions in East and Southeast Asia. Journal of International Marketing, 10(2), 29-45.

Keller, K. L. (1993). Conceptualizing, Measuring, and Managing Customer-based Brand Equity. Journal of Marketing, 57(1), 1-22.

Kotler, P. H. (1991). Marketing Management: Analysis, Planning, Implementation, and Control (7th ed.). Englewood Cliffs, NJ: Prentice-Hall, Inc.

Li, F., \& Shooshtari. (2003). Brand Naming in China: Sociolinguistic Implications. The Multinational Business Review, 11(3), 3-18.

Marcel, D. (2013). Semiotizing a Product into a Brand. Social Semiotics, 23(4), 464-476, http://dx.doi.org/10.1080/10350330.2013.799003

McCarthy, E. J., \& Perreault, W. D. Jr. (1987). Basic Marketing: A Management Approach (9th ed.). Irwin, Homewood, IL.

McNeal, J. U., \& Zeren, L. M. (1981). Brand Name Selection for Consumer products. MSU Business Topics, Spring, 35-39.

Miller, J., \& Muir, D. (2004). The Business of Brands. San Francisco: Wiley Press.

Peterson, R. A., \& Ross, I. (1972). How Name New Brands. Journal of Advertising Research, 12(6), 29-34.

Ren, R. (2002). Principles of Designing the English Trademarks from the Perspective of Economic Value. Language Teaching, 5, 17-20.

Robertson, K. (1989). Strategically Desirable Brand Name Characteristics. Journal of Consumer Marketing, 6(4), 61-71.

Schmitt, B., \& Zhang, S. (2012). Selecting the Right Brand Name: An examination of Tacit and Explicit Linguistic Knowledge in Name Translations. Journal of Brand Management, 19(8), 655-665, http://dx.doi.org/10.1057/bm.2011.62

Zhou, C., Hou, L., \& Xing, H. (2002). Brand Culture: Connotation, Philosophy and Representation of Commodity Culture. Beijing: Economy and Management Publishing House.

\section{Copyrights}

Copyright for this article is retained by the author(s), with first publication rights granted to the journal.

This is an open-access article distributed under the terms and conditions of the Creative Commons Attribution license (http://creativecommons.org/licenses/by/3.0/). 